\title{
Tip II Diabetes Mellitus'ta Kutanöz Sessiz Periyod
}

\author{
Sibel ÜSTÜN ÖZEK ${ }^{1}$, Serpil KUYUCU YILDIZ², Nebil YILDIZ ${ }^{2}$
}

\begin{abstract}
$\ddot{\mathbf{O} z}$
Diabetik sensorimotor polinöropatide küçük lif tutulumunu göstermekte kutanöz sessiz periyodun (KSP) diğer elektrofizyolojik yöntemlere ve klinik muayeneye bir üstünlük taşıyıp taşımadığı, tutulan liflere ek olarak A-Delta liflerindeki anormalliği göstermekte ne düzeyde katkı sağlayacağının araştırılması planlandı. 51 Diabetes Mellitus (DM) Tip II'li olgu ve 19 adet normal olgu incelendi. İki alt ve bir üst ekstremitede motor ve duysal iletiler, Tibial F yanıt, H refleksi ve KSP kaydı yapıldı. Hasta grubu H refleks latans, tibial ileti hızı, minimal Tibial F yanıt latansı ve sural sinir duysal yanıt amplitüdlerinde rastlanan anormalliklere göre normaller A Grubu, iki testinde pozitif sonuç alınanlar B grubu ve üç ya da dört testte patoloji saptananlar C grubu olarak sınıflandırıldı. Grupların kendi aralarında ve kontrollerle sonuçları karşılaştırıldı. Sonuç olarak KSP başlangıç latansının hasta grubunda, özellikle de $\mathrm{C}$ grubu kontrollerle karșılaștırıldığında anlamlı olarak geciktiği tespit edildi $(\mathrm{p}=0,008)$. KSP süresi ve bitiş latansında buna benzer bir değişiklik saptanmadı. Tibial sinir motor yanıt ileti hızı kontroller ile B ve $C$ grubu arasında anlamlı fark vard $1(p=0,008$ ve $p=0,000)$. B ve $C$ grubunda Tibial F yanıt latans1 sirasiyla $(p=0,008$ ve $p=0,000)$ ve $H$ refleks latans1 da sırasıyla $(\mathrm{p}=0,002$ ve $\mathrm{p}=0,000)$ istatistiksel anlamlı uzun saptandı. Başlangıç latansındaki bu gecikmenin diabette diğer duysal uyarıları taşıyan liflerle birlikte belirgin A-Delta tutulumunu gösteriyor olabileceğini düşündürmüştür. Hafif ve orta düzeyde polinöropatisi olanlarda KSP anormalliği gözlenmezken ciddi polinöropatisi olanlarda KSP başlangıç latansının anlamlı uzun olduğu görülmüştür.
\end{abstract}

Anahtar Kelimeler: Diabetes mellitus, Kutanöz sessiz periyod, A-delta lifleri

\section{Cutaneous Silent Periods in Type II Diabetes Mellitus}

Sibel ÜSTÜN ÖZEK ${ }^{1}$, Serpil KUYUCU YILDIZ ${ }^{2}$, Nebil YILDIZ ${ }^{2}$

\begin{abstract}
We aimed to test whether cutaneous silent period (CSP) is superior or not to the other electrophysiological tests and also to clinical examination to show small fiber involvement and also to show A Delta fiber anomalies in diabetic sensory motor neuropathy. We tested 51 DM Type II patients and 19 normal healthy subjects. Motor and sensory conduction velocities, tibial nerve $\mathrm{F}$ wave responses, $\mathrm{H}$ reflexes and CSP recordings were done in two lower an done upper extremity. According to the abnormalities observed in $\mathrm{H}$ reflex latencies, tibial nerve conduction velocities, minimal Tibial $\mathrm{F}$ wave latencies and sural nerve action potential amplitudes in patients group, patients with no abnormality were grouped into $\mathrm{A}$, and if there were two abnormalities into B, and if there were three or more abnormalities into C. Groups were compared with each other and with control subjects. The onset latency of CSP especially in C group was significantly longer in patients group when compared with controls $(\mathrm{p}=0.008)$. However, the duration and the ending latencies of CSP were not different. In tibial nerve motor conduction velocities in control subjects were significantly different from $\mathrm{B}$ and $\mathrm{C}$ group ( $\mathrm{p}=0.008, \mathrm{p}=0.000$ respectively). Tibial $\mathrm{F}$ wave latency $(\mathrm{p}=0.008, \mathrm{p}=0.000)$ and $\mathrm{H}$ reflex latency $(\mathrm{p}=0.002, \mathrm{p}=0.000)$ were significantly late in $\mathrm{B}$ and $\mathrm{C}$ groups. These findings observed in onset latencies suggest us that $\mathrm{A}$ delta fibers were also involved in DM. While in mild or moderate sensory neuropathy, CSP abnormalities could not be found, in severe neuropathy the onset latency of CSP was significantly late.
\end{abstract}

Article Info

Received:16.11.2018

Accepted:22.01.2019

Online Published:30.06.2019

DOI: $10.26453 /$ otjhs. 484278

Corresponding Author

Sibel ÜSTÜN ÖZEK

Sağlık Bilimleri Üniversitesi, Okmeydanı Eğitim ve Araştırma Hastanesi,Nöroloji Kliniği,İstanbul,Türkiye sibelustun@hotmail.com Tel: 00905325969090

Keywords: Diabetes mellitus, cutaneous silent period, A-delta fibers

\footnotetext{
${ }^{1}$ Sağlık Bilimleri Üniversitesi,Okmeydanı Eğitim ve Araştırma Hastanesi,Nöroloji Kliniği, İstanbul,Türkiye

${ }^{2}$ Abant İzzet Baysal Üniversitesi,Nöroloji Kliniği,Bolu,Türkiye.
} 


\section{GíRiș}

Diabetes Mellitus (DM); insülin yetersizliğine veya etkisizliğine bağlı olarak gelişen karbonhidrat, protein ve yağ metabolizmasında bozukluklara yol açan kronik hiper glisemik bir metabolizma hastalığıdır. Diabetik olgularda polinöropati görülme sıklığı yapılan bir metaanalizde tip I diabetlilerde \%8-63, Tip II diabetli olgularda \%13-51 olarak bildirilmiştir. ${ }^{1}$ En sik distal duysal ve otonomik polinöropati görülür. Kranyal nöropati ve mononöropatiler de izlenir. $^{2}$

İstemli olarak kasılan bir kasın elektromiyografik aktivitesi periferik olarak mikst ya da kutanöz duysal bir sinirin mekanik ya da elektriksel uyanılmasıyla, santral olarak elektriksel kortikal ve transkranial manyetik stimülasyon (TMS) ile geçici bir süre için mutlak ya da göreceli olarak durdurulabilir. ${ }^{3}$ $\mathrm{Bu}$ geçici aktivite azalması sessiz period (SP) olarak

isimlendirilmiştir. SP yanıtlarında, bu refleks arkını oluşturan afferent-santral-efferent yollarından herhangi birini etkileyen olaylarda, örneğin radikülopati, kök avülsiyonları, myelopatide anormalliklere rastlanacaktır. ${ }^{4}$ DM da hem afferent hem de efferent yolları etkilemektedir.

Kutanöz sessiz periyod (KSP) istemli olarak kasılan bir kasın aktivitesinin ağrılı kutanöz bir stimulusla geçici süre ile durdurulmasıdır. ${ }^{5}$
Elektriksel stimulasyon ile çok sayıda ve farklı sınıftaki kutanöz afferentler aktive olmasına rağmen, KSP oluşumunda küçük çaplı, ince myelinli, yüksek uyarılma eşiğine sahip ve yavaş ileten afferentlerin esas sorumlu olduğuna dair çok sayıda kanıt elde edilmiştir. KSP' yi elde edebilmek için yüksek yoğunlukta stimulus verilmesinin gerekli olması bu kanıtlardan birisidir. Bu stimuluslar ağrılı olarak hissedilirler. Duysal aksiyon potansiyelleri ve somatosensoriel uyarılmış potansiyelleri elde edilemeyen duysal nöropatililerde KSP 'lerin normal sinırlarda elde edilmesi de büyük çaplı liflerin primer olarak görevli olmadığını göstermiştir. $\mathrm{Bu}$ lifler rutin incelemeler sirasinda yüzeyel kayıtlamada çok az katkısı olan liflerdir. Bu özellikleri bu lifleri A-Delta sınıfına sokmaktadır. ${ }^{6}$ A-delta lifleri yavaş ileten, ince miyelinli ve ağrılı uyaranları taşıyan liflerden oluşmaktadır.

DM'ta en sik rastlanan sensorimotor polinöropati'de duysal tutulumun ön planda olduğu, küçük çaplı liflerin de ciddi bir şekilde etkilendiği bilinmektedir. KSP'nin hangi parametrelerinin, ne şekilde takip edileceği çok iyi bilinmemekle birlikte diabetik sensorimotor polinöropatinin herhangi bir döneminde küçük lif tutulumunu göstermekte KSP'nin diğer elektrofizyolojik yöntemlere ve klinik muayeneye bir üstünlük taşıyıp taşımadığı, tutulan liflere ek olarak A-Delta 
liflerindeki anormalliği göstermekle ne düzeyde katkı sağlayacağını araştırmak amaçlanmıştır.

\section{MATERYAL VE METOT}

Çalışmamızda toplam 51 adet DM Tip II'li ve 19 adet normal olgu incelenmiştir. DM' li 51 hastanın 27'si kadın, 24'u erkek, 19 kontrol olgunun 8'i kadın, 11 tanesi erkekti. Hasta grubunun ortalama yaşı 55,5, kontrol grubunun ortalama yaşı 50,9 idi. Kontrol grubu, bilinen herhangi bir, özellikle de polinoropati ile seyredebilecek böbrek yetmezliği ve vitamin eksikliği, kanser ve kemoterapi öyküsü, alkol ve madde kullanım öyküsü ve radiküler şikayetleri olmayan sağlıklı gönüllü olgulardan oluşturuldu. Diabetli grupta ortalama hastalık süresi 73,7 ay (minimum 2 - maksimum 240 ay) olarak hesaplanmıştır. Hasta grubuna şikayeti olsun ya da olmasın diabet tanısı almış olgular dahil edilmiştir. Çalışma prospektif olarak planlanmış ve altı ay içerisinde tamamlanmıştır. Tüm hastaların EMG incelemeleri kliniğimiz elektrofizyoloji laboratuvarında yapılmıştır. Çalışma için etik kurul onayı alınmış ve tüm bireylerden onam alınmıştır.

Bütün kontrollere ve hastalara elektrofizyolojik (iki alt ve bir üst ekstremitede motor ve duysal iletiler kaydedildi) inceleme yapıldı. Hasta grubu sural sinir duysal yanit amplitüdü, tibial sinir F yanıtları, soleus kası $\mathrm{H}$ refleksi ve tibial sinir motor ileti hızları göz önüne alınarak bu parametrelerden hiçbirinde patoloji olmayanlar ve sadece bir tanesinde patoloji elde edilenler A grubu, iki tanesinde patoloji elde edilenler B grubu, üç ya da dört tanesinde patoloji saptandığında ise $\mathrm{C}$ grubu olarak gruplara ayrılmıştır. Yakınma olarak ayaklarda özellikle geceleri olan paresteziler ve uyuşukluk pozitif kabul edilmiş, bunun olup olmamasına göre hasta grubu olarak ikiye ayrılmıştır. Bütün hastaların detaylı nörolojik muayeneleri yapılmıştır. Patolojik bulgusu saptananlar ve nörolojik muayenesi normal olanlar, bulgu $(+)$ ve bulgu (-) olarak iki alt grup şeklinde ayrılmıştır. Elektrofizyolojik olarak sural sinir duysal yanıt amplitüdü için $10 \mathrm{uV}$, alt ekstremite motor ileti hızı için $40 \mathrm{~m} / \mathrm{sn}$ sınır değer olarak belirlenmiş, bunun altındaki değerler patolojik olarak kabul edilmiştir. Tibial sinir F yanıtı ve soleus kası $\mathrm{H}$ refleksi için

boya göre normogramlara bakılarak patolojik değerler belirlenmiştir (Shin J. Oh'un önerdiği şekilde $)^{7}$ Hasta ve kontrollerin bacak boyları L1- posterior iliak superior noktası arasındaki mesafe ile bu noktadan ayak ucuna kadar olan mesafe toplanarak elde edilmiştir. Elektrofizyolojik incelemeler Medelec Synergy 5 Channel EMG-EP cihazı ile yapılmıştır. KSP için hasta ve kontrollerin 
hepsinde, olgu yüzüstü yatar durumda iken inceleme yapılmış, maksimal eforla gastrocnemius-soleus kas grubunu kastırılmıştır. Süpürme süresi $200 \mathrm{~ms}$, birim amplitüd $0.5 \mathrm{mV}$ olarak ayarlanmıştır. Sural sinir dış malleol ardından $300 \mathrm{mV}(100 \mathrm{~mA})^{\prime}$ luk kare dalga uyarısı ile ve 0,2-0,5 ms süreyle stimüle edilmiştir. Arka arkaya 8-10 yanıt kaydedilmiş, uyarılar gelişigüzel aralıklarla (en fazla saniyede $1 \mathrm{~Hz}$ sıklıkla) verilmiştir. Soleus kası üzerinden yüzeyel elektrod ile kayıtlama yapılmıştır.

Ölçümlerde mutlak sessizlik dönemi kullanılmış, hasta ve kontroller için KSP' nin başlangıç latansı, süresi ve bitiş latansı belirlenmiştir. Soleus kası $\mathrm{H}$ refleks yanıtları diz ardından tibial sinir uyarımı ve soleus kası üzerinden yüzeyel kayitlama ile elde edilmiştir. Tibial sinir F yanıtları iç malleol ardından tibial sinir supramaksimal olarak uyarılmış ve A. Hallucis kası üzerinden yüzeyel elektrod ile kaydedilmiştir. Arka arkaya 10 yanıt kaydedilmiş bu yanıtların içinde en kısa latanslı olan yanıt ölçümlerde kullanılmıştır.

Verilerin değerlendirilmesinde SPSS 14,0 paket programı kullanıldı. İstatistiksel olarak unpaired student T-test ve Anova Tukey-HSD testleri uygulandı. Tüm değişkenlere ait tanımlayıcı istatistikler ve değişkenlerin ortalamaları aritmetik \pm standart sapma şeklinde gösterildi. Yapılan istatistiksel analizlerde anlamlılık düzeyi $\mathrm{p}<0,05$ olarak alındı.

\section{BULGULAR}

Bacak boyu ortalamas1 hasta grubunda 107,8 $\mathrm{cm}$, kontrol grubunda $108,42 \mathrm{~cm}$ di. Bulgusu olan toplam 21 hasta, nörolojik muayenesi normal olan 30 hasta bulunmaktayd1. Ellerde ve ayaklarda yanma ve uyuşma şikayeti olan 28 hasta, şikayeti olmayan 23 hasta bulunmaktayd1. A grubunda 20 kişi, B grubunda 13 kişi, C grubunda 18 kişi vardi. Tüm hasta grubunda KSP başlangıç latansı ortalaması $98,7 \pm 11,55 \mathrm{~ms}$, süre ortalaması $57,19 \pm 11,66 \mathrm{~ms}$, bitiş latansı ortalaması $156,13 \pm 13,77 \mathrm{~ms}$ olarak elde edilmiştir. Kontrol grubunun KSP başlangıç latansı ortalamas1 $94,2 \pm 8,97 \mathrm{~ms}$, süre ortalamas1 $60,34 \pm 10,99 \mathrm{~ms}$, bitiş latansı ortalaması $154,54 \pm 19,63 \mathrm{~ms}$ olarak elde edilmiştir. Regresyon analizlerinde KSP başlangıç ve bitiş latanslarının boyla ve hastanın yaşıyla korele olmadığı gözlendi. Çoklu karşılaştırmalarda KSP başlangıç latansında kontrol grubu ve A ve B grupları arasinda istatistiksel olarak anlamlı fark tespit edilmemişken, $\mathrm{C}$ grubu ile istatistiksel olarak anlamlı fark elde edilmiştir $(p=0,008)$. A grubu ile $B$ ve $C$ grupları karşılaştırıldığında elde edilen değerler istatistiksel olarak anlamlı bulunmuştur (sırasılyla $p=0,028$ ve $p=0,000$ ).

KSP süresi ve bitiş latansı açısından kontrollerle hiç bir grup arasında anlamlı fark tespit edilmedi (Tablo 1). 
Tibial sinir motor yanıt ileti hızları ortalaması hasta grubunda $42,95 \pm 4,8 \mathrm{~m} / \mathrm{sn}$ (minimum 33,0 $\mathrm{m} / \mathrm{sn}$-maksimum $54,5 \mathrm{~m} / \mathrm{sn}$ ), kontrol grubunda ise $\quad 46,9 \pm 2,7 \mathrm{~m} / \mathrm{sn} \quad$ minimum $43 \mathrm{~m} / \mathrm{sn}$ maksimum $53,0 \mathrm{~m} / \mathrm{sn}$ ) olarak elde edilmiştir. Tibial sinir motor yanıt ileti hızı açısından çoklu karşılaştırmalarda; kontroller ile B ve C grubu arasinda anlamlı fark vard $1(p=0,008$ ve $\mathrm{p}=0,000)$. Kontroller ve A grubu arasinda anlamlı fark tespit edilmedi. C grubu ile kontroller, A ve B grupları arasında istatistiksel olarak çok anlamlı fark vardı $(\mathrm{p}=0,000$ ve $\mathrm{p}=0,000)$.

Bir hastada sural sinir duysal yanıtı kaydedilememiş, 50 hastanın sural sinir duysal yanıt amplitüd ortalaması $13,82 \pm 7,13 \mu \mathrm{V}$ (minimum $2,9 \mu \mathrm{V}$-maksimum $35,0 \mu \mathrm{V}$ ) olarak tespit edilmiştir. Kontrol grubunun sural yanıt amplitüd ortalaması $22,72 \pm 7,03 \mu \mathrm{V}$ (minimum $13,1 \mu \mathrm{V}$-maksimum $38,5 \mu \mathrm{V}$ ) olarak elde edilmiştir.Sural sinir duysal yanıt amplitüdleri açısından çoklu karşılaştırmalarda, kontrol grubu ile A grubu arasında istatistiksel olarak anlamlı fark yoktu $(\mathrm{p}=0,052)$. Ancak B ve C grupları ile karşılaştırıldığında kontrol grubunun değerleri istatistiksel olarak anlamlı olacak derecede yüksekti $(p=0,017$ ve $p=$ 0,000). C grubunun değerleri kontrol, A ve B grupları ile karşılaştırıldığında anlamlı olarak daha düşük amplitüdlüydü $(p=0,000, p=0,000$ ve $\mathrm{p}=0,001)$.

Tibial $\mathrm{F}$ yanıtı latans (minimal) ortalaması hasta grubunda51.2 $\pm 5,8 \mathrm{~ms} \quad$ (minimum 34,65ms-maksimum 64,8ms) olarak elde edilmiştir. Kontrol grubunun ortalaması 45,8 $\pm 2,65 \mathrm{~ms}$ (minimum 42,0ms-maksimum $51,75 \mathrm{~ms}) \quad$ olarak hesaplanmıştır. Minimal tibial F yanıt latansı açısından çoklu karşılaştırmalarda, Kontrol ve A grubu arasinda anlamlı fark saptanmazken, B ve C grubu ile elde edilen farklar anlamliyd $(\mathrm{p}=0,008$ ve $\mathrm{p}=0,000$ ) $\mathrm{C}$ grubu hem kontrollerle hem de A ve B grubu ile karşılaştırıldığında istatiksel olarak anlamlı derecede uzamışt1.

3 hastada $\mathrm{H}$ refleks yanitları elde edilememiştir. 48 hastanın $\mathrm{H}$ refleks latans ortalamas1 $31,6 \pm 3,3 \mathrm{~ms}$ (minimum 23,3msmaksimum $37,85 \mathrm{~ms}$ ) olarak tespit edildi. Kontrol grubunda ortalama latans $28,5 \pm 1,6 \mathrm{~ms}$ (minimum 25,45-maksimum 30,8ms) olarak elde edildi. H refleks latansı açısından çoklu karşılaştırmalarda, kontrol grubu ve A grubu arasında anlamlı fark edilmedi. B ve C grupları ile anlamlı fark vardı $(p=0,002$ ve $\mathrm{p}=0,000) \mathrm{C}$ grubu hem kontrollerle hem de A ve B grupları ile karşılaştırıldığında anlamlı olarak gecikmiști (Tablo 2).

\section{TARTIŞMA VE SONUÇ}

KSP istemli olarak kasılan bir kasın elektromyografik aktivitesinde, kutanöz bir sinirin supramaksimal elektriksel uyarılmasını takiben gözlenen relatif ya da mutlak aktivite azalmasıdır. $^{8} \quad$ KSP rutin elektrofizyolojik 
incelemelerden daha çok spinal kordun fonksiyonel organizasyonu ve bu sistem üzerinde etkili supraspinal mekanizmaların araştırılmasında kullanılmaktadır. Spinal motor nöronun eksitabilitesinin araştırılması amacıyla koşullandırılmış çalışmalar yapılmış, bu amaçla $\mathrm{F}$ yanıtı ve $\mathrm{H}$ refleksle birlikte KSP çalışılmıştır. Bu çalışmaların sonucunda bunun spinal inhibitör bir refleks olduğu ve kısmen supraspinal modulasyona uğradığ gösterilmiştir. ${ }^{9} \mathrm{Bu}$ refleksin afferentleri Adelta sınıfına uyan yavaş ileten, ince myelinli ve ağrılı uyaranlar taşıyan liflerden oluşmaktadır. Refleksin spinal motor nöronlar üzerinde inhibisyon yapan ortak internöronlar aracılığıyla olduğu düşünülmekte ve bu internöronlar arasında da en çok Renshaw hücrelerinin üzerinde durulmaktadır. Daha çok spinal fizyolojik organizasyonun araştırılmasında kullanılmakla birlikte, bugüne kadar distoni, syringomyeli, Parkinson hastalığı), Huntington koresi ve benzeri hastalıkların tanısında ve fizyopatolojisini ortaya koymada bu testin işlerliği üzerine çok sayıda çalışma yapılmıştır. Multisistem atrofili hastalarda yapılan bir çalışmada KSP latansının belirgin gecikmiş olduğu ve süresinin sağlıklı kontollere göre uzun olduğu saptanmıştır. Levodopa tedavisi ile de anlamlı bir değişiklik saptanmamış ve bu da hastalığın levodopaya yanıtsızlığına bağlanmıştır. ${ }^{10}$ Özellikle syringomyelide diğer elektrofizyolojik testlerden daha önce bozulduğu ortaya konmuştur. ${ }^{11}$ KSP nin spinal patolojileri ortaya koymakta ve değerli olduğu ortaya konmuştur. Buradan hareketle periferik sinir sisteminde etkinliğin olup olmadı̆̆ klinik bulgulara bir üstünlüğünün olup olmayacağı, bize erken tanı konusunda desteği olabilir mi düşüncesi ile çalışmayı planlandık. Ancak bu yöntemle sensorimotor polinöropatilerde hafif bir tutulumu göstermekten uzak olduğunu saptadık.

Hemodiyalize giren hastalarda özellikle küçük A delta liflerinde etkilenme olduğu ve bunları değerlendirmek için rutin elektrofizyolojik çalışmalarla tespit edilemeyen ileti anormalliklerinin tespit edilmesinde KSP nın faydalı olduğunu saptamışlardır Özellikle KSP başlanıç latansı uzamış, süre değişmemiş olarak saptanmıştır. ${ }^{12}$ Biz de çalışmamızda özellikle polinöropati bulguları daha ağır olan olgularda KSP nin başlangıç latansını uzun saptadık. KSP süresi bizim olgularımızda da değişmemiş saptand1.

Fabry hastalığında küçük çaplı liflerin tutulumu gösterilmeye çalışılmış, kutanöz sessiz periyodun küçük lif fonksiyonlarının klinik değerlendirilmesinde önemli bir yöntem olduğundan hareket edilmiş, bazı olgularda anormallikler saptanmakla birlikte bu testin, normal klinik yöntemlere bir üstünlüğünün olmadığı, hafif ve orta düzeyde termal duyu kaybı olanlarda KSP nin normal olarak ele edilebileceğini saptamışlardır. ${ }^{13} \mathrm{Bu}$ çalışmada 
da bizim çalışmamızdaki gibi hastalık şiddeti hafifken KSP nin katkısı olmamıştır.

Karpal tünel sendromlu (KTS) olgularda KSP latansı uzun saptanırken sürede değişiklik saptamamışlardır. Ancak latans uzaması ile hastalık şiddeti arasında korelasyon saptamamışlardır. ${ }^{14}$ Bir başka çalışmada KTS de hastalık şiddeti ilerledikçe A-delta lifleri de etkilenmiştir. Hastalık şiddeti ilerledikçe de KSP latansı gecikmiş saptanmıştır. ${ }^{15}$ Hastalık şiddeti ile korelasyon olduğunu söyleyen çalışmalar yanında olmadığını belirtenler de vardır. Biz olgularımızda karpal tünel varlığını ayrıca değerlendirmedik ancak polinöropati şiddeti açısından değerlendirildiğinde bizim çalışmamız hastalık ilerledikçe etkilenmenin belirginleştiğini ortaya koymaktadır.

Çalışmamız sonucunda polinöropati tanısı alan hastalarda en fazla anormallik saptama olasılığı sırasıyla minimal F yanıt latansında, $\mathrm{H}$ refleks latansinda ve sural sinir duysal yanıtında tespit edilmiştir.

Hafif ve orta düzeyde polinöropatisi olanlarda KSP anormalliği gözlenmezken, ciddi polinöropatisi olanlarda KSP başlangıç latansının anlamlı uzun olduğu görülmüştür. Hastanın yakınmaları küçük lif tutulumunu göstermekle birlikte KSP normal saptanmıştır. Ancak belirgin A-delta lifi tutulumunda ya da A-delta liflerinin hastalığın daha geç dönemlerinde etkilenmesine bağlı olarak ancak belirgin polinöropatilerde anormal bulgular saptanması açıklanabilir. Küçük lif tutulumu düşünülen olgularda $\mathrm{C}$ lifi tutulumunun sorumlu olduğu düşünülebilir. Demiyelinizan ve aksonal özellikli plinöropatilerin karşılaştırıldığı bir çalışmada KSP süresinin demiyelinizan grupta uzadığı, aksonal grupta ise demiyelinizan ve normallare göre kısa olduğu gösterilmiştir. Nöropatik ağrı şiddeti ile bir ilişki saptanmamış ağrı şiddeti ile korele bulunmamıștır. ${ }^{16}$ Diyabetli hastalarda yapılan bir çalışmada büyük lif tutulumu olanlarda KSP süresi daha uzun bulunmuştur. KSP süre uzunluğu sinir ileti çalışmaları ve geç cevaplarla anlamlı korele bulunmuştur. ${ }^{17} \mathrm{KSP}$ incelemesi polinöropatilerde belirgin A-delta lifi tutulumunun varlığını ortaya koyabilecek bir yöntem olarak gözükmektedir. Üremik hastalarda yapılan bir çalışmada kontrollere göre latans uzun ve süre değişmemiş olarak bulunmuştur. ${ }^{12}$ Fibromiyaljide latans uzunluğu spinal koruyucu refleksin inhibe edici bölümünde gecikme olduğunu göstermektedir. Spinal ve supraspinal seviyelerde sensorimotor entegrasyon evrelerindeki anormallik ile ilgilidir. $^{18}$ KSP daha çok spinal anormalliklerde ve lezyon lokalizasyonu ve patofizyolojisini aydınlatmada değerli bir yöntemdir. KSP ile ilgili çalışmalar halen devam etmektedir. Sağlıklı gönüllülerde yapılan bir çalışmada spinal proprioseptif proseslerin distal ve proksimal kaslarda farklı olduğu saptanmıştır. Distal kaslarda başlangıç latansı erken, süre uzun ve supresyon düzeyi en küçük saptanmışken, proksimal kaslarda 
başlangıç latansı geç, refleks süresi kısa ve refleks en büyük bulunmuștur. $\mathrm{Bu}$ da spinal inputların oldukça karmaşık olduğu ve KSP nin mekanizmasının hala belirsizliğini koruduğunu ve bu alanda çok çalışmaya ihtiyaç olduğunu göstermektedir. ${ }^{19}$

Bizim çalışmamızda KSP diyabetik sensorimotor polinöropatilerde hafif bir tutulumu göstermemektedir. KSP' nin başlangıç latansı özellikle sural duysal yanıt amplütüdü, tibial sinir $\mathrm{F}$ yanıtı, $\mathrm{H}$ refleksi ve tibial sinir motor ileti hızı değerlendirildiğinde bu parametrelerin 3 ya da 4 'ünde patoloji saptanan olgularda belirgin olmak üzere anlamlı oranda gecikmiş saptanmıştır. KSP süresi ve bitiş latansında değişiklik saptanmamıştır. Başlangıç latansındaki bu gecikmenin diabette diğer duysal iletileri taşıyan liflerle birlikte belirgin A-delta tutulumunun göstergesi olabileceği düşünülmüştür.

\section{KAYNAKLAR}

1. Ziegler D, Papanas N, Vinik AI, Shaw JE. Epidemiology of polyneuropathy in diabetes and prediabetes. Handb Clin Neurol. 2014;126:3-22.

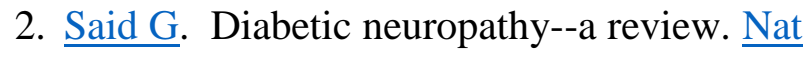
Clin Pract Neurol. 2007;3(6):331-40.

3. Öge AE, Yayla V. Uyandırılmış Potansiyeller. Klinik Nörofizyoloji İncelemeleri in; Öge AE, Baykan B. ed.
Nöroloji. 2. Bask1. İstanbul: Nobel T1p Kitabevleri. 2011;143-153.

4. Leis $\underline{\text { AA, }}$ Kofler M, Stetkarova I, Stokic DS . The cutaneous silent period is preserved in cervical radiculopathy: significance for the diagnosis of cervical myelopathy Eur Spine J. 2011;20(2):236-9.

5. Floeter MK. Cutaneous silent periods Muscle \& Nerve.2003:331-401.

6. Snell Richard S.Clinical Neuroanatomy 7 thed ,USA. Lippincott Wiliams Wilkins.2010.

7. Shin J.Oh. Clinical electromyograph. Nerve conduction studies. Third edition. Lippincott Wiliams Wilkins. 2003.

8. Yoon TS, Han SJ, Lee JE, Park DS, Jun AY. Changes in the cutaneous silent period by paired stimulation. Neurophysiol Clin. 2011;41(2):67-72.

9. Manconi FM, Syed NA, Floeter MK. Mechanisms underlying spinal motor neuron excitability during the cutaneous silent periods in humans. Muscle Nerve. 1998;21:1256-1264.

10. Stetkarova I, Kofler M, Majerova V. Cutaneous silent periods in multiple system atrophy. Biomed Pap Med Fac Univ Palacky Olomouc Czech Repub. 2015;159(2):327-32.

11. Stetkarova I, Kofler M, Leis AA. Cutaneous and mixed nerve silent periods in syringomyelia. Clinical Neurophysiology. 2001;112(1):78-85. 
12. Tiric-Campara $\mathrm{M}$, Denislic $\mathrm{M}$, Tupkovic et al. Cutaneous silent period in the assessment of small nerve fibers in patients on hemodialysis. Med Glas (Zenica). 2014;11(2):270-5.

13. Syed NA, Sandbrink F, Luciano CA, et al.Cutaneous silent periods in patients with Fabry disease. Muscle Nerve. 2000;23(8):1179-86.

14. Koo YS, Park HR, Joo BE et al. Utility of the cutaneous silent period in the evaluation of carpal tunnel syndrome. $\underline{\text { Clin }}$ Neurophysiol. 2010;121(9):1584-1588.

15. Duarte JM, D'Onofrio HM, Rolón JI, Bertotti AC. The impairment of A-delta fibers in median nerve compression at the wrist, using the cutaneous silent period . Medicana (B Aires). 2016;76(4):219-22.

16. Lopergolo D, Isak B, Gabriele M, et al.Cutaneous silent period recordings in demyelinating and axonal polyneuropathies. Clin neuruphsiol. 2015;126(9):1780-9.

17. $\underline{\operatorname{Kim} B J}, \underline{\operatorname{Kim} \mathrm{NH}}, \underline{\operatorname{Kim} \mathrm{SG}}$, et al. Utility of the cutaneous silent period in patients with diabetes mellitus. J neurol sci. 2010;15;293(1-2):1-5.

18. Sahin O, Yildiz S, Yildiz N. Cutaneous silent period in fibromyalgia. Neurol res. 2011;33(4):339-43.

19. Eckert NR, Poston B, Riley ZA. Differential processing of nociceptive input within upper limb muscles. Plos One. 2018;25;13(4):e0196129. 
Tablo 1. Hasta ve kontrollerin kutanöz sessiz süre başlangıç süre ve bitiş latansları.

\section{Hasta}

Minimum

Maksimum

Ortalama \pm SD

Kontrol

Minimum Maksimum

\begin{tabular}{|c|c|c|c|c|c|c|c|}
\hline $\begin{array}{l}\text { KSP başlangıç latansı } \\
(\mathrm{ms})\end{array}$ & $98,7 \pm 11,55$ & 74,8 & 127,3 & $94,2 \pm 8,98$ & 79,4 & 110,0 & $\begin{array}{l}\mathrm{A}: 0,817^{*} \\
\mathrm{~B}: 0,178 * * \\
\mathrm{C}: 0,008 * * * \\
\mathrm{~A}: 0.999\end{array}$ \\
\hline KSP süre (ms) & $57,19 \pm 11,66$ & 32,7 & 83 & $60,34 \pm 10,99$ & 47,9 & 87,6 & $\begin{array}{l}\text { B:0,998 } \\
\text { C:0,059 } \\
A: 0,954\end{array}$ \\
\hline KSP bitiş latansı (ms) & $156,1 \pm 13,77$ & 120 & 188,1 & $154,6 \pm 9,63$ & 136,3 & 171,7 & $\begin{array}{l}B: 0,260 \\
C: 0,997\end{array}$ \\
\hline
\end{tabular}

*A :sural duysal yanıt amplütüdü,tibial sinir F yanıtı,H refleksi ve tibial sinir motor ileti hızı değerlendirildiğinde bu parametrelerin 1 'inde patoloji saptanan grup ${ }^{* *} \mathrm{~B}: 2$ 'sinde patoloji saptanan grup ${ }^{* * *} \mathrm{C}: 3$ ya da 4 'ünde patoloji saptanan grup 
Tablo 2. Hasta ve kontrol grubunun Hrefleks minimal tibial F latansları sural sinir duysal yanit amplütüdleri ve tibial motor yanıt ileti hızı ortalamaları standart deviasyonlar, minimum ve maksimum değerler.

\begin{tabular}{|c|c|c|c|c|c|c|c|}
\hline & \multicolumn{3}{|c|}{ Hasta } & \multicolumn{3}{|c|}{ Kontrol } & \multirow[b]{2}{*}{$\mathbf{p}$} \\
\hline & Ortalama $\pm \mathrm{SD}$ & Minimum & Maksimum & Ortalama $\pm \mathrm{SD}$ & Minimum & Maksimum & \\
\hline $\begin{array}{l}\text { H Refleks Latans } 1 \\
(\mathrm{~ms})\end{array}$ & $31,6 \pm 3,3$ & 23,3 & 37,9 & $28,5 \pm 1,65$ & 25,45 & 30,8 & $\begin{array}{l}\mathrm{A}: 0,609 * \\
\mathrm{~B}: 0,002 * * \\
\mathrm{C}: 0,000 * * *\end{array}$ \\
\hline $\begin{array}{l}\text { Tibial Minimum F } \\
\text { Latansı (ms) }\end{array}$ & $51,2 \pm 5,8$ & 34,65 & 64,8 & $45,8 \pm 2,65$ & 42,0 & 51,75 & $\begin{array}{l}A: 0,754 \\
B: 0,008 \\
C: 0,000\end{array}$ \\
\hline Sural Amplütüd $(\mu \mathrm{V})$ & $13,8 \pm 7,1$ & 2,9 & 35,0 & $22,7 \pm 7,03$ & 13,1 & 38,5 & $\begin{array}{l}\mathrm{A}: 0,052 \\
\mathrm{~B}: 0,017 \\
\mathrm{C}: 0,000\end{array}$ \\
\hline $\begin{array}{l}\text { Tibial Sinir İleti Hizı } \\
(\mathrm{m} / \mathrm{sn})\end{array}$ & $42,96 \pm 4,8$ & 33 & 54,5 & $46,87 \pm 2,7$ & 43 & 53,0 & $\begin{array}{l}A: 1,000 \\
B: 0,008 \\
C: 0,000\end{array}$ \\
\hline
\end{tabular}

A :sural duysal yanıt amplütüdü,tibial sinir $\mathrm{F}$ yanıtı,H refleksi ve tibial sinir motor ileti hızı değerlendirildiğinde bu parametrelerin 1'inde patoloji saptanan grup ${ }^{* *} \mathrm{~B}: 2$ 'sinde patoloji saptanan grup ${ }^{* * *} \mathrm{C}: 3$ ya da 4 'ünde patoloji saptanan grup 